Psychological Medicine, 1977, 7, 369-371

Printed in Great Britain

\title{
EDITORIAL
}

\section{Transcultural psychiatry should begin at home'}

In 1976, transcultural psychiatry can be said to have attained its majority, both because its journal ${ }^{2}$ was then 21 years old and because an international congress ${ }^{3}$ was devoted to it for the first time. As its name implies, it is concerned not just with international comparisons (Kraepelin's 'vergleichende Psychiatrie') nor with racial differences (the French 'ethnopsychiatrie') but specifically with culture in the anthropological sense, i.e. with values, beliefs, habits and structure which a society passes from one generation to the next. (The 'trans' implies comparison, but of these values, etc.) Not all that gets published in its name shares this concern directly, but there is a general acceptance that culture in the sense given above is capable of affecting mental disorder and its treatment, so that when the term 'transcultural' is attached to a study this implies that one expects (or fears) that cultural factors are affecting the psychiatric picture. Moreover, in the better transcultural studies one regularly finds reference to the ways in which factors of known concern to psychiatry-factors such as family structure, the role of the therapist and the ideal self-image-depend on culture. It is the contribution of such studies to both the practice and the theory of psychiatry which accounts mainly for the steady growth of the field.

Yet in this growth there has been a curious paradox. In all other branches of psychiatry, advances in practice and in theory have derived largely from, and have concerned themselves largely with, the major societies of Western Europe and North America. In contrast, the great bulk of the literature on transcultural psychiatry is concerned with other societies, principally African, Asian and Amerindian. This fact is so obvious, even if the authors usually come from Western Europe or America, that it provokes on the one hand the complaint that transcultural psychiatry is perpetuating colonialist attitudes, and on the other hand the question whether the major Western societies have nothing truly cultural to call their own.

Two explanations for this state of affairs come readily to mind, both of them carrying the implication that transcultural psychiatry does not need to come nearer home and both of them unsatisfactory on closer examination. The first is that formal studies of a transcultural nature are unnecessary in developed countries, since their cultures are too well known to the psychiatrists practising there. It is when these psychiatrists must deal with people from a foreign culture, so runs this argument, that the guidance of new studies is needed. The second explanation is that we are merely dealing with a confusion of labels, since what goes under the heading of transcultural psychiatry when one is dealing with Asians or Africans is really no different from what goes under the headings of family psychiatry, social psychiatry or descriptive epidemiology when one is dealing with Westerners.

Each of these explanations bears some truth, since one is most aware of the need for cultural analysis when dealing with a foreign patient, and since many reports bearing the transcultural label go no more deeply into the cultural roots of phenomena than psychiatric studies of familial and other social factors in developed countries do. Each of them also, however, is insufficient on further examination, and a little library research will show one that they are defensive rationalizations rather than incomplete generalizations. If one reads a paper comparing, explicitly or implicitly, mental disorders in an Asian and a Western society, one will, if lucky, find an attempt to link the excess of conversion hysterias in the former group to the particular Asian culture involved but one

\footnotetext{
1 Address for correspondence : Professor H. B. M. Murphy, Section of Transcultural Psychiatric Studies, McGill University, 1266 Pine Avenue West, Montreal, Canada, H3G 1A8.

- Transcultural Psychiatric Research Review (McGill-Queen's University Press, Montreal, Canada).

3 International Congress on Transcultural Psychiatry, Bradford, England, July 1976.
} 
will virtually never find an equivalent attempt to link the excess of alcoholism or adolescent delinquency to the Western culture's influences. Carstairs (1954) has written a valuable discussion, with psychiatric inferences, of the reasons why some groups in India prefer cannabis, some alcohol and some opium, but there is no comparable discussion of the differences between behavioural norms in the Irish pub, the French bistro and the Bavarian Bierkeller. The cultural background to the Oedipus complex has been closely examined with respect to developing societies as far apart as Senegal (Ortigues \& Ortigues, 1966) and Korea (Lee, 1972), but there is very little written about its vicissitudes across Europe. When the World Psychiatric Association sponsored a symposium on 'Comparative Transcultural Psychiatry within Europe' (at Kiel, April 1976) nearly all the contributors spoke about immigrants from other parts of Europe and virtually none about their own cultures. The truth is, therefore, that European and North American psychiatrists are not merely pursuing transcultural studies of their own societies under other names, or knowing the facts too well to need them put on paper; they are evading the issue, and this is a phenomenon which demands our attention.

To almost everyone, the behaviour and expectations developed in his own culture appear 'natural' or 'logical' while those deriving from other cultures appear unnatural, culture-specific, or arising from abnormal conditions. Hence, when a foreign-born patient behaves in unexpected fashion, the average psychiatrist today may ask himself what it is in that patient's cultural background which has led to this behaviour, but he is not at all likely to ask himself what it is in his own culture and that of his more familiar patients that led to another type of behaviour being expected. Similarly, if he happens to have an assistant from the patient's own culture and asks that assistant for an explanation of the cultural roots of the observed behaviour, he may be disappointed with the apparent superficiality of the answer but he is most unlikely to ask himself whether he would be able to do any better at explaining the cultural bases of his own behaviour. The common failure to examine the relationship between behaviour and the values or beliefs of one's own culture (with adequate recognition of the fact that other cultures hold other values) is in part habit and in part a defence of one's own value system. To psychiatrists, all types of psychological defence are of some interest, but it will take considerable effort to breach the resistances which are part of that defence, and that effort carries some risk. One can end up not knowing which values to adhere to. Hence, although the matter demands attention, it can legitimately be asked whether one should direct that attention at one's own culture or only, as has largely occurred until now, at the culture of others.

This question is essentially the same as asking whether psychotherapists should attempt to explore their own unconscious processes, and calls for the same answer. Freud's (1910) dictum that 'no psychoanalyst goes further than his own complexes and internal resistances permit' applies here likewise. We can practise psychiatry without self-analysis, but only at a superficial level. We can treat patients and plan preventive programmes without asking how far the target problems are linked to culturally based values, habits, etc.; but likewise only at a superficial level. One of the major questions which the International Pilot Study of Schizophrenia (WHO, 1973) has highlighted (but not answered) is whether the relatively higher chronicity of schizophrenia in developed than in developing countries (Murphy \& Raman, 1971) arises from certain social or psychological orientations in the former societies. We are not going to answer this question only through studies in Nigeria and India; the developed societies also need to be investigated. Fortunately, the rapidity of social change is making this easier for us today, since the culture of the under-30s is in many countries changed from that which the over-50s acquired, regardless of social class, and this is leading us to tolerate a certain degree of cultural relativism. However, as with psychoanalysis, it is better that one embarks on such analyses of one's own culture with some professional aid from the type of person whom the anthropologist Weidman has called a 'culture-broker', a psychiatrically sophisticated social scientist or person with a foot in both social science and medicine (Weidman, 1977). Alternatively, one could commence by inviting internationally experienced transcultural psychiatrists from other cultures, such as Neki (1976) and Kimura (1971), to provide us with more of their observation on ourselves.

In any event, the time is overdue when the relationship between cultural backgrounds and 
psychopathology or forms of therapy in developed countries should be more formally examined, and when we should cease thinking that our behavioural expectations are all 'natural', not requiring re-examination.

H. B. M. MURPHY

\section{REFERENCES}

Carstairs, G. M. (1954). Daru and Bhang - Cultural factors in the choice of an intoxicant. Quarterly Journal of Studies on Alcohol 15, 220

Freud, S. (1910) (republished 1957). Complete Psychological Works, vol. 11, p. 145. Hogarth Press : London.

Kimura, B. (1971). Mitmenschlichkeit in der Psychiatrie. Ein transkultureller Beitrag aus Asiatischer Sicht. Zeitschrift für Klinische Psychologie und Psychotherapie 19, 3.

Lee, K. D. (1972). Initiation rites and castration phobia. (In Korean.) Neuropsychiatry (Seoul) 11, 109.

Murphy, H. B. M. \& Raman, A. C. (1971). The chronicity of schizophrenia in indigenous tropical peoples. British Journal of Psychiarry 118, 489-497.
Neki, J. S. (1976). An examination of the cultural relativism of dependence as a dynamic of social and therapeutic relationships. The British Journal of Medical Psychology 49, 1-22.

Ortigues, M.-C. \& Ortigues, E. (1966). Oedipe Africain. Plon : Paris.

Weidman, H. H. (1977). Implications of the culture broker concept for the delivery of health care. Social Science \& Medicine 10, (In the Press).

World Health Organization (1973). Report of The International Pilot Study of Schizophrenia, vol. 1. World Health Organization: Geneva. 